$\begin{array}{lll}\text { H A N S K L E N, P O E T A } & \text { K }\end{array}$ 


\section{UN POEMA DE HANS KELSEN}

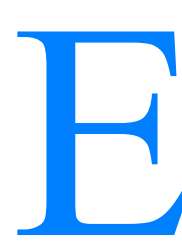

121 de abril de 1967 visité a Hans Kelsen en su casa ubicada en Los Angeles Ave. en Berkeley, California. Esta calle está ubicada en un lugar especialmente hermoso, donde se elevan los árboles cargados de lluvia, en un ambiente de verde humedad. Cuando llegué a la puerta de la casa, tuve la visión de la silueta de Kelsen, de pie, trabajando sobre unos documentos, recortada su figura azul sobre el diamante de luz de una gran ventana. Llamaba la atención su estatura, pequeña, que contrastaba fuertemente con su poderosa frente, que como una bóveda, albergaba todos los conocimientos y experiencias por los que se le considera el jurista más importante de este siglo.

La amabilidad y cordialidad austriacas son proverbiales, pero en Kelsen aparecían con una suavidad y naturalidad que podría decirse constituían una segunda naturaleza. En el visitante, esto producía un efecto de sorpresa y admiración, pues se estaba frente a uno de los juristas más importantes de la historia, el creador de la escuela teórica del Derecho más conspicua del siglo XX, el redactor de la Constitución austriaca de 1920, amigo personal de Freud y otros grandes de la época dorada de la decadencia de la Viena del Imperio Austro-Húngaro, que fue la Atenas de este moribundo siglo, manantial de todas las corrientes culturales que lo han alimentado. La cordialidad asomaba su dulzura en cada gesto de Kelsen, la cual no era perturbada por los entusiasmos explosivos que podía producirle una idea interesante o novedosa.

Antes de conversar sobre los temas de la teoría del Derecho que yo había preparado con el objeto de conocer su opinión, me condujo directamente a una pequeña sala, muy modesta, constituida por tres piezas de mobiliario, frente a una chimenea de una extrema sencillez. En este cuarto sólo había una gran ventana, al fondo, por donde entraba la luz de los días brillantes de abril, desde la que podía contemplarse las explosiones florales de los colores de varias rosas y otros especímenes que le gustaba cultivar. Recuerdo que tenía sobre su escritorio y en la pared retratos de Kant, Freud, Einstein 
y el de alguna mujer muy bella, que le parecía «arrebatadoramente hermosa». A mi pregunta de la razón por la que tenía el retrato de Freud en su escritorio, contestó diciendo que era «por la forma tan completa como Freud se había identificado con su propia teoría». Le pregunté sobre su amistad con el creador del psicoanálisis y me relató un acontecimiento de un amigo suyo, abogado de profesión, que había caído en una profunda neurosis, en relación con ciertos acontecimientos relacionados con su hijo pequeño de dos años; Freud pudo ayudarle a salir de sus angustias, con una sola entrevista de dos horas, la tarde en que lo recibió en su consultorio. Me dijo, contestando una pregunta, que había sido amigo cercano de Otto Weininger, el cual se había suicidado, como tantos en Viena, por la razón más extraña que cupiera pensar: había llegado a la conclusión, después de muchas consideraciones, de que era un asesino y para evitar realizar su propensión al homicidio, prefirió quitarse la vida. Frente a la chimenea, del otro lado de la habitación, había un librero que contenía la totalidad de las publicaciones de sus obras, en varios idiomas.

Kelsen mismo preparó un exquisito café, muy concentrado; lo sirvió en la taza, le puso azúcar, lo movió y, ya preparado, lo colocó frente a mí. Me ofreció un cigarro, más bien, un pequeño puro, «a very soft cigar», se sirvió su brebaje, tomó una galleta y entera la introdujo en la boca. Con esto, la plática comenzó.

Yo había preparado varios temas de conversación, con objeto de que me aclarara algunas dudas sobre la Teoría Pura del Derecho. Estos temas eran referentes al criterio para determinar el marco de interpretación que constituye toda norma, la dualidad entre la Estática y la Dinámica jurídicas y la posibilidad de construir la Teoría del Derecho prescindiendo de la primera, sobre la coacción como el concepto definitorio del Derecho, sobre la preferencia teórica de aceptar el primado del orden jurídico internacional sobre el nacional y otros temas relacionados con el concepto de la revolución. La conversación duró casi tres horas. Me informó sobre los ensayos que estaba escribiendo sobre «Derecho y Lógica».

Cada intercambio de opiniones le producía un entusiasmo verdaderamente sorprendente, para un hombre de su edad: tenía en sus manos varios hilos teóricos de la historia y, por tanto, su entusiasmo era explosivo, sincero, amistoso y concentrado. Estaba entregado completamente a la elaboración de teorías e ideas iluminadoras de muchas oscuridades de su objeto de conocimiento. Me comentó que era viejo y que ya no le gustaba viajar, pero que no dudaría en ir al otro extremo del mundo para discutir alguna idea novedosa en el campo de sus investigaciones.

La plática se había prolongado, pues tratamos adicionalmente problemas muy difíciles como las posibles relaciones entre la moral y el Derecho, así como el carácter normativo de las normas morales. Me ofreció un segundo cigarro, que fumamos con deleite. En ese momento, manifestó que tenía deseos de citar un verso. Me preguntó sobre mi conocimiento del alemán 
y tuve que informarle de mi ignorancia del idioma. Entonces, pareció desistir de su intento, lo que me produjo la sensación de que estaba a punto de perder una joya. Tomé la oportunidad como se presentaba y le pregunté sobre el autor del verso, con la secreta intención de buscarlo con posterioridad y saber, de esa manera, cuáles eran los sentimientos que cruzaban por su pecho. Me dijo que el verso era suyo. Le pedí que me lo tradujera.

Prefirió escribirlo, para que yo lo tradujera posteriormente en México. Se sentó a escribirlo y, en unos cuantos segundos, interrumpió su actividad. Se levantó, fue a sus papeles y sacó una hoja original, escrita de su puño y letra. La firmó y me lo obsequió. Este poema se publica por vez primera y revela una faceta de Kelsen que hasta ahora no era conocida.

Nuevamente, en la despedida, pude comprobar que la sutileza, profundidad y grandeza de su pensamiento tenían una correspondencia exacta en sus sentimientos.

\section{CARPE DIEM}

Bald, Ach Bald wirst du erblassen,

Diese schöne Welt verlassen

Und vergessen sein.

Darum sollst du dich nicht sorgen;

Stets ist Heute, me ist Morgen;

Zeit ist Schein.

Allzufernes nicht erträumen,

Dich kann naher Glück verräumen.

Nur was du ergreifst ist dein!

\section{CARPE DIEM}

Pronto, Oh! pronto tu empalidecerás,

Dejarás este bello mundo

Y serás olvidado.

Por ello no debes preocuparte,

Siempre es hoy, nunca es mañana;

El tiempo es ilusión

No ensueñes lo muy lejano,

Puedes dar lugar a dichas cercanas.

¡Sólo lo que tomas es tuyo! 
36

Ulises Schmill Ordóñez

Carpe diem

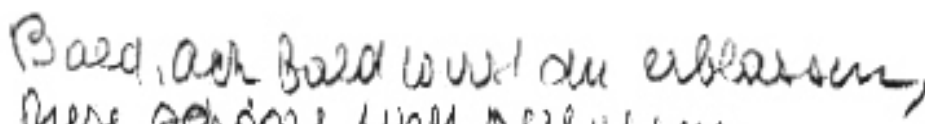

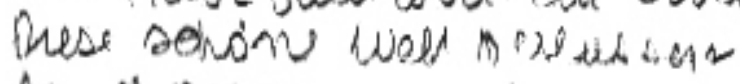

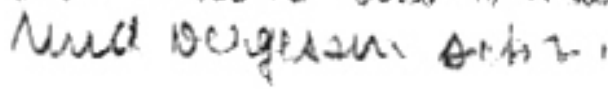

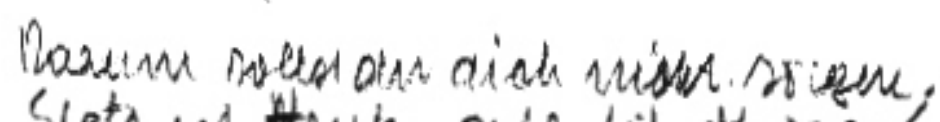

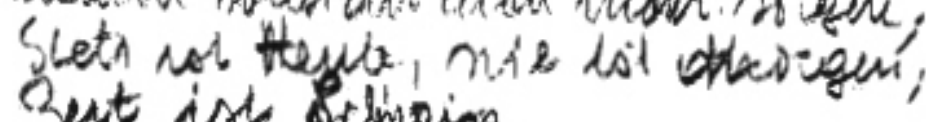
zeut ist sonion.

Hesaptermes most estiourmon,

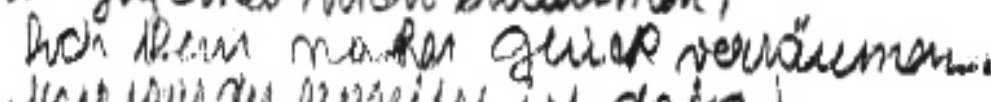

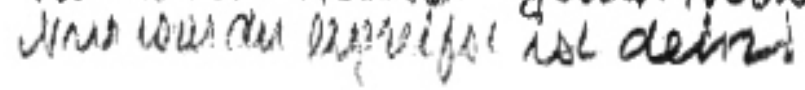

Transtienen

DOXA 19 (1996) 